\title{
New ideas for teaching electrocardiogram interpretation and improving classroom teaching content
}

\author{
This article was published in the following Dove Press journal: \\ Advances in Medical Education and Practice \\ 10 February 2015 \\ Number of times this article has been viewed
}

\author{
Rui Zeng' \\ Rong-Zheng Yue ${ }^{2}$ \\ Chun-Yu Tan ${ }^{3}$ \\ Qin Wang ${ }^{4}$ \\ Pu Kuang 5 \\ Pan-Wen Tian ${ }^{6}$ \\ Chuan Zuo ${ }^{3}$ \\ 'Department of Cardiovascular \\ Diseases, ${ }^{2}$ Department of Nephrology, \\ ${ }^{3}$ Department of Rheumatology \\ and Immunology, ${ }^{4}$ Department \\ of Endocrinology, ${ }^{5}$ Department \\ of Hematology, ${ }^{6}$ Department of \\ Respiratory Diseases, West China \\ Hospital, School of Clinic Medicine, \\ Sichuan University, Chengdu, People's \\ Republic of China
}

Background: Interpreting an electrocardiogram (ECG) is not only one of the most important parts of diagnostics but also one of the most difficult areas to teach. Owing to the abstract nature of the basic theoretical knowledge of the ECG, its scattered characteristics, and tedious and difficult-to-remember subject matter, teaching how to interpret ECGs is as difficult for teachers to teach as it is for students to learn. In order to enable medical students to master basic knowledge of ECG interpretation skills in a limited teaching time, we modified the content used for traditional ECG teaching and now propose a new ECG teaching method called the "graphics-sequence memory method."

Methods: A prospective randomized controlled study was designed to measure the actual effectiveness of ECG learning by students. Two hundred students were randomly placed under a traditional teaching group and an innovative teaching group, with 100 participants in each group. The teachers in the traditional teaching group utilized the traditional teaching outline, whereas the teachers in the innovative teaching group received training in line with the proposed teaching method and syllabus. All the students took an examination in the final semester by analyzing 20 ECGs from real clinical cases and submitted their ECG reports.

Results: The average ECG reading time was 32 minutes for the traditional teaching group and 18 minutes for the innovative teaching group. The average ECG accuracy results were $43 \%$ for the traditional teaching group and $77 \%$ for the innovative teaching group.

Conclusion: Learning to accurately interpret ECGs is an important skill in the cardiac discipline, but the ECG's mechanisms are intricate and the content is scattered. Textbooks tend to make the students feel confused owing to the restrictions of the length and the format of the syllabi, apart from many other limitations. The graphics-sequence memory method was found to be a useful method for ECG teaching.

Keywords: new ideas, ECG, classroom teaching content, graphics-sequence memory

\section{Introduction}

Diagnostics is an important area of medical knowledge, and an electrocardiogram (ECG) is not only among the most important diagnostic tests but also one of the most difficult topics to teach. As a basic test in clinical work, the ECG plays a key role in the diagnosis of cardiovascular disease. With the incidence of cardiovascular disease noticeably higher at present than in the past, ${ }^{1}$ the ECG has been increasingly used in clinical work. Owing to the abstract nature of the basic theoretical knowledge of the ECG, its scattered characteristics, and tedious and difficult-to-remember subject matter, this subject is difficult for teachers to teach and for medical students to learn. ${ }^{2,3}$ Besides, the theoretical knowledge of the ECG is so difficult for students to understand that they
Correspondence: Chuan Zuo Department of Rheumatology and Immunology, West China Hospital, School of Clinic Medicine, Sichuan University, 61004I, Chengdu, People's Republic of China

Tel +862885422343

$\mathrm{Fax}+862885423249$

Email zengrui_0524@I26.com 
tend to resort to traditional rote learning, which often leads to difficulties and errors in clinical interpretation of ECGs. Students tend to be unenthusiastic while learning about the ECG, and its reputation as a difficult concept causes some students to resist learning it and others to give up altogether. If these problems cannot be solved, not only could ECG teaching not meet teaching requirements, but it could also affect the ability of medical students in clinical work to correctly read ECGs in the future. Therefore, we must modify traditional teaching ideas and develop new teaching methods to improve the quality of ECG teaching.

In order to enable medical students to master basic knowledge of ECG interpretation skills in the limited teaching time, we summarized our experiences acquired through many years of clinical ECG teaching and revised the content of traditional ECG teaching. Now, we propose a new ECG teaching and learning model called the "graphics-sequence memory method" to obtain improved results when teaching ECG interpretation skills.

\section{Method}

\section{Graphics-sequence memory method basics}

Here we introduce two important concepts related to the proposed graphics-sequence memory method. The first one is "graphics," which refers to schematic diagrams of normal and abnormal ECGs given to students that let the students be intuitive and clearly understand the morphology of normal and abnormal ECG (Figures 1 and 2). The second concept is the "sequence" to be followed when analyzing ECGs; the students should follow a specific sequence of the production of the ECG waveform that involves step-by-step analysis of the heart rate and rhythm, P wave, PR interval period, QRS wave, ST segment and T wave, as well as QT interphase until $\mathrm{U}$ wave (Figure 3 and Table 1).

\section{Difference between traditional Chinese ECG teaching method and graphics- sequence memory method}

Traditional Chinese ECG teaching methods always follow the sequence and pattern mentioned in teaching materials;

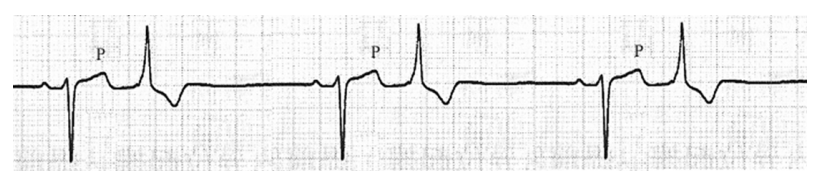

Figure I Schematic diagram of atrial premature beats with conduction of interior differences.

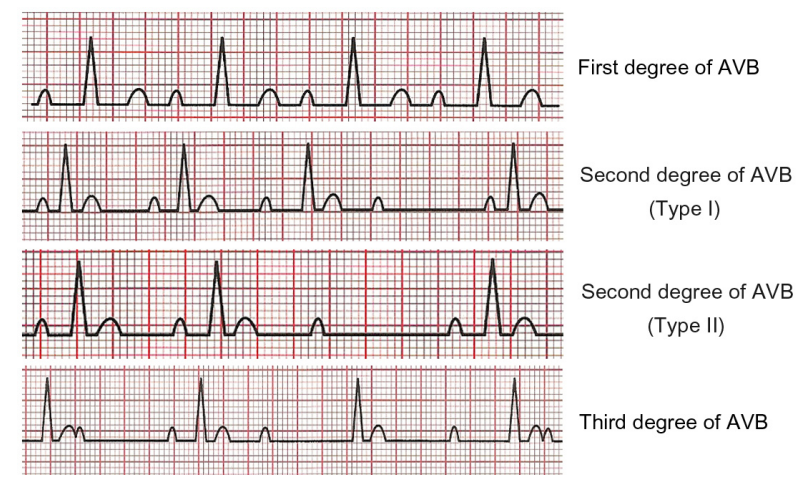

Figure 2 Schematic diagrams of atrioventricular block (AVB).

hence the ECG study and interpretation is based on different diseases for which typical ECGs are shown during teaching. For example, the students have always been taught by showing the ECGs corresponding to acute myocardial infarction, acute myocarditis, pulmonary embolism, and so on. Besides, ECG skills are taught to junior students (Grade 3) in Chinese medical education, but specific medical courses such as internal medicine and surgery are taught to senior students (Grade 4). In other words, the students who learn the ECG at this stage have not undergone any specialization courses; consequently, they cannot diagnose diseases correctly. Owing to this limitation, the traditional ECG teaching method often fails to ensure satisfactory learning outcomes.

The traditional Chinese ECG teaching method can therefore be called a disease-based teaching method. On the other hand, the graphic-sequence memory method proposed on the basis of our cumulative teaching experience does not depend on diseases for ECG teaching but on the graphics and sequence of the ECG itself. Many schematic diagrams are shown to help the students remember key aspects, while the sequence is used as a scientific method to help the students understand. Using this novel approach, we have obtained improved results when teaching ECG in People's Republic of China.

\section{Prospective randomized controlled study to measure actual ECG learning outcomes}

Ethics statement

The study was conducted with prior institutional ethical approval under the requirements of the Chinese Law for the Prevention of Cruelty to Human Subjects and the Code of Practice for the Care and Use of Human Subjects for Scientific Purposes. All human subjects of this study were inspected by members of the Human Subject Ethics Committee of West 

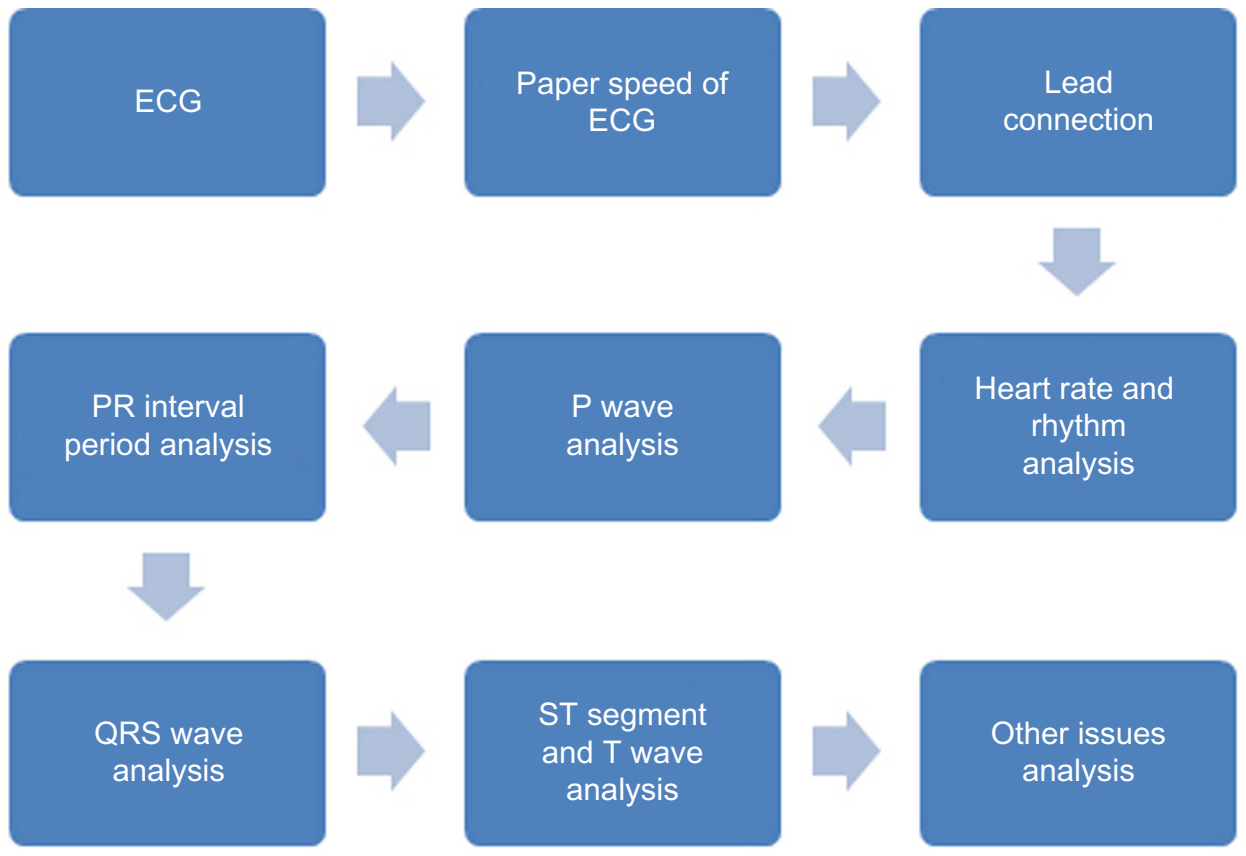

Figure 3 Analysis diagram of electrocardiogram (ECG) by graphics-sequence memory method.

China Medical Center (HSPC20130102-12547) and the study complied with the Declaration of Helsinki.

\section{Study participants}

Two hundred junior students in the school of clinical medicine were chosen by cluster sampling using a computer-based random selection method. The study was a randomized. 200 students were divided by auxiliary teaching office teacher who was on the premise of fully knowing, according to their

Table I Electrocardiogram (ECG) content analysis by graphicssequence memory method

\begin{tabular}{lll}
\hline Analysis content & Normal & Abnormal \\
\hline Heart rate & $60-100$ per & $<60$ per minute \\
& minute & $>100$ per minute \\
Heart rhythm & Regular & Irregular \\
P wave & Sinus P wave & Non-sinus P wave \\
PR interval period & $0.12-0.20$ & $<0.12$ seconds \\
& seconds & $>0.20$ seconds \\
QRS wave & Normal & Abnormal voltage \\
& QRS wave & Abnormal electric axis \\
& & QRS duration augmentation \\
& & Pathological Q wave \\
ST segment & Normal & Elevation and depression of \\
& ST segment & ST segment \\
T wave & Normal & Tip, flat, or inverted T wave \\
& T wave & \\
Other issues & & U wave \\
& & Abnormal electrolyte- \\
& & related ECG \\
& & Drug-related ECG \\
& &
\end{tabular}

student number corresponding to determine categories. This included 100 students into the innovative teaching group (the experiment group), and another 100 students into the traditional teaching group (the control group).

\section{Research methods}

Textbooks and curriculum setting

Both two groups use the same authority textbook of diagnostics for national higher medical colleges and universities (the seventh edition of Diagnostics edited by Professor Chen Wenbin, People's Medical Publishing House), and also the same practice guidance, classroom teachers, teaching progress and test form. Teachers in the traditional teaching group utilized the traditional teaching outline, whereas teachers in the innovative teaching group received training in the new teaching method and syllabus.

\section{Evaluation method}

All students took an examination in the final semester by analyzing 20 ECGs from real clinical cases and submitted their ECG reports. The average reading times and accuracies were recorded to compare the performances of the two groups and to test the effect of teaching using the new method. Five experienced cardiologists decided on the standard answer for the 20 ECGs given to the students.

\section{Statistical methods}

Using SPSS17.0 statistical software, measurement data were expressed by $\bar{x} \pm \mathrm{s}$, and comparing the two groups of 
independent sample $t$-test, while counting data by $\chi^{2}$ test, $P<0.05$ for the inspection level.

\section{Results}

\section{Baseline situation of students between two groups}

With respect to the sex composition ratio, age, and the basic course grades, there was no significant difference between the two groups $(P>0.05)$ (Table 2$)$.

\section{Average ECG reading times and accuracies for two groups}

For the two groups, the average ECG reading time was calculated. The average ECG reading time was 32 minutes for the traditional teaching group and 18 minutes for the innovative teaching group. The average ECG accuracy was 43\% for the traditional teaching group and $77 \%$ for the innovative teaching group. The results are shown in Figure 4. All data were statistically significant, further proving that the new teaching method is effective and practical, and should be worth implementing on a larger scale.

\section{Discussion}

ECG learning is an important skill required in the cardiology discipline, but the ECG's mechanisms are intricate, and the learning content is scattered. Textbooks tend to make students feel confused owing to the restrictions of the length and format of the syllabi, as well as many other limitations. For these reasons, teachers feel ECG teaching is difficult, and students feel ECG learning is difficult. ${ }^{4}$ The authors feel quite strongly about the need for better preparation of ECG teaching lessons and believe that learning outcomes will not be satisfactory if only the content of ECG textbooks is

Table 2 Baseline situation of students between two groups

\begin{tabular}{|c|c|c|c|c|}
\hline Variables & $\begin{array}{l}\text { Experiment } \\
\text { group } \\
(n=100)\end{array}$ & $\begin{array}{l}\text { Control } \\
\text { group } \\
(n=100)\end{array}$ & $\begin{array}{l}t \text {-value or } \\
\chi^{2} \text { value }\end{array}$ & $P$-value* \\
\hline $\begin{array}{l}\text { Sex composition } \\
\text { (male/female) }\end{array}$ & $59 / 41$ & $57 / 43$ & 1.19 & 0.28 \\
\hline Age (years) & $21.47 \pm 1.43$ & $21.33 \pm 2.07$ & 0.77 & 0.41 \\
\hline $\begin{array}{l}\text { Humanities } \\
\text { module }\end{array}$ & $83.23 \pm 2.20$ & $83.56 \pm 2.52$ & -0.62 & 0.54 \\
\hline $\begin{array}{l}\text { Body } \\
\text { morphology } \\
\text { module }\end{array}$ & $80.19 \pm 6.45$ & $80.15 \pm 7.31$ & 0.02 & 0.98 \\
\hline Physiology & $77.63 \pm 7.59$ & $76.52 \pm 8.47$ & 0.62 & 0.54 \\
\hline Pathophysiology & $88.58 \pm 6.30$ & $86.69 \pm 7.88$ & 1.20 & 0.24 \\
\hline Pathology & $80.5 \pm 5.20$ & $81.33 \pm 5.60$ & -0.70 & 0.49 \\
\hline
\end{tabular}

Note: *Compared with the control group. Data are shown as mean \pm standard deviation.

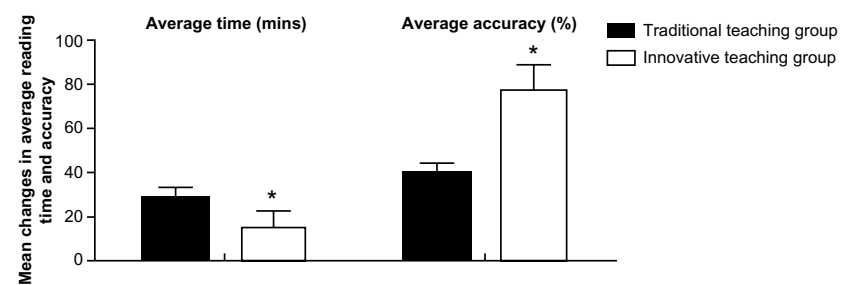

Figure 4 Average electrocardiogram (ECG) reading time and accuracy achieved by traditional teaching group and innovative teaching group. Note: $* P<0.05$ compared with traditional teaching group.

completely used for teaching. Therefore, our ECG teaching team put forward a new, creative method of ECG teaching the graphics-sequence memory method - and it has been fully used in our ECG teaching process with good results.

To evaluate the effectiveness of this new teaching method, a prospective randomized controlled study was conducted. According to the results of the study, we could easily indicate that both the average ECG reading time and ECG accuracy are much better in the innovative teaching group compared with that in the traditional Chinese teaching group. How could we achieve good teaching effect? As we mentioned before, ECG was taught to junior students (Grade 3 ) in the Chinese medical education schedule, but all other specific medical courses, including internal medicine and surgery, were taught to senior students (Grade 4). Naturally, students who learn about ECGs at this earlier stage could not identify the diseases correctly as the students had no exposure to specialized courses. It is because of this limitation that the traditional ECG teaching method often failed to obtain satisfactory learning outcomes.

Although we could not change the Chinese medical education schedule, we could adapt our teaching method to suit the situation and achieve our teaching goals. The graphic-sequence memory method was developed on the basis of our cumulative teaching experience and used in our ECG teaching. In our method, the focus of ECG teaching is transferred to the graphic and sequence of the ECG itself. Many diagrammatic sketches are shown to students to help remember, while the sequence is used as a scientific method to help the students to better interpret the ECGs. Thus, we obtained improved results when teaching the ECG using the new method in People's Republic of China.

Notwithstanding the good teaching method newly developed, other issues related to the basic education of the ECG cannot be ignored. On the basis of our teaching experience, we believe for teaching the ECG well, the following three goals need to be achieved:

First, improve the students' interest in learning the ECG and their recognition of the importance of studying the ECG. 
Teachers should first emphasize the clinical value of the ECG and ensure that the students understand that ECG examination is an important auxiliary examination method. It has become an important basis for disease diagnosis and an effective rescue clue for critically ill patients. ${ }^{5,6}$ In addition, teachers need to ensure that students realize that the ECGs are a superior and irreplaceable method for diagnosing diseases such as myocardial infarction and arrhythmia in typical cases and to make them clearly understand that they will be able to make quick judgments and emergency treatment choices of some diseases according to ECG results once in clinical practice. Through the use of multimedia teaching and the reading and analysis of ECG reports, combined with clinical cases, it is possible to gradually cultivate the students' interest in learning about the ECG, to change the students' learning and understanding from passive to active, and to improve the students' ability to master comprehensive analysis and application of ECGs.

Second, the basis of the clinical case teaching model, repeated practice, and summaries should be emphasized. The reason medical students must learn the theoretical background of ECGs is to enable the students to complete their clinical diagnosis and treatment work in medical practice. To allow students to apply their knowledge flexibly in medical practice, they are required to master a large number of clinically common and significant ECG findings in their limited ECG courses. This mastery entirely depends on repeated readings of numerous ECGs. Teachers collect various typical or complex ECGs from cases in their clinical work, arrange them into an atlas, and attach a brief clinical data summary. During teaching, students make an ECG diagnosis and record their diagnosis and analysis for their teachers to respond to with questions or comments. Through repeated reading, it is possible to enhance the students' ability to think and make judgments independently and to fully mobilize the students' enthusiasm towards learning. Combining the use of clinical cases is valuable because students will then avoid the mentality of "only knowing what it is, but not knowing why." In addition, teachers should repeatedly remind students that ECGs could be very different from the typical textbook examples because of the complexity of clinical diseases. ${ }^{7,8}$ Therefore, students should not separate ECG results from patients but should combine ECG results with the patient's clinical symptoms and medical examination. Doing so will help them make correct ECG diagnoses and avoid misdiagnoses or missed diagnoses. ${ }^{9}$

Third, comprehension of teachers have to be improved. Whether students display an interest in learning about ECGs and grasp the intricacies of ECGs largely depends on their teacher's teaching level and skills. Teachers should not only be familiar with the teaching content but should also have a rich clinical background, a solid and profound foundation of medical knowledge, and should be good at making vivid, detailed and accurate descriptions. Teachers should also be able to constantly update their teaching ideas to further improve their ability to communicate with students and to stimulate students' interest in ECG learning.

The ability to inspire students' imaginations and creativity is also very important. For example, how does one explain the atrioventricular block (AVB)? Teachers could let students know that the PR interval period could be compared with the relationship between two lovers, with $\mathrm{P}$ and $\mathrm{QRS}$ waves, respectively, representing a man and woman in love. When a I degree AVB occurs, it could be understood as a romantic relationship in which some inharmonious ingredients have led to alienation in the relationship, as represented by the extension of the PR interval period in the ECG; when a II degree and type I AVB happens, it could be understood as similar to a situation when the relationship between the two people has become worse making them quarrelsome, with them sometimes appearing to ignore each other, as represented by the PR interval period extending gradually until an omission of the P wave in the ECG occurs. When a II degree and type II AVB happens, it could be understood as a situation when the relationship between the two people deteriorates further. Although not quarrelling often, the couple ignore each other, and such a situation can be used to explain the fact that while the PR interval period does not change, the P wave suddenly disappears in the ECG. When a III degree AVB occurs, it could be understood as two people with no relationship, as the relationship has come to an end, similar to the way that the P and QRS waves are completely independent of each other in the ECG.

Teachers should also strengthen their interdisciplinary knowledge, be more comprehensive in their work, learn from the excellent teaching experience of others, and constantly keep open their field of vision. Finally, they should try to use a variety of flexible teaching methods to improve and perfect their teaching ability, such as multimedia teaching and various forms of case discussions and illustration analyses. ${ }^{10-15}$

\section{Conclusion}

ECG learning is an important requisite of the cardiac discipline, but the ECG's mechanisms are intricate, and the learning content is scattered. Textbooks tend to make students feel confused owing to the restrictions of the length and format 
of the syllabi, as well as many other limitations. Our ECG teaching team put forward a new, creative method of ECG teaching - the graphics-sequence memory method - and it has been successfully used in our ECG teaching process, producing good results.

\section{Acknowledgment}

This research was supported by the China Medical Board (CMB-00-721).

\section{Disclosure}

The authors report no conflicts of interest in this work.

\section{References}

1. Murray CJL, Lopes AD. The Global Burden of Diseases: A Comprehensive Assessment of Mortality and Disability from Diseases, Injuries, and Risk Factors in 1990 and Projected to 2020. Boston: Harvard School of Public Health; 1996.

2. Little B, Mainie I, Ho KJ, Scott L. Electrocardiogram and rhythm strip interpretation by final year medical students. Ulster Med J. 2002; 71(1):96.

3. Mikael N, Gunilla B, Claes H, Bo-Lennart J, Uno F, Jan Ö. Evaluation of a web-based ECG-interpretation programme for undergraduate medical students. BMC Med Educ. 2008;8:25.

4. Martin ML, Lewis RJ, Yealy DM. ECG competency-by whom, for whom? Acad Emerg Med. 2002;9(4):348.
5. Trzeciak S, Erickson T, Bunney EB, Sloan EP. Variation in patient management based on ECG interpretation by emergency medicine and internal medicine residents. Am J Emerg Med. 2002;20(3):188-195.

6. Berger JS, Eisen L, Nozad V, et al. Competency in electrocardiogram interpretation among internal medicine and emergency medicine residents. Am J Med. 2005;118:873-880.

7. Brna P, Cox R. Adding intelligence to a learning environment: learnercentred design? J Comput Assisted Instr. 1998;14:268-277.

8. Salerno SM, Alguire PC, Waxman HS. Training and competency evaluation for interpretation of 12-lead electrocardiograms: recommendations from the American College of Physicians. Ann Intern Med. 2003;138:747-750.

9. Hatala R, Norman GR, Brooks LR. Impact of a clinical scenario on accuracy of electrocardiogram interpretation. J Gen Intern Med. 1999;14:126-129.

10. Harris J, Salasche S, Harris R. The Internet and the globalization of medical practice. Br Med J. 2001;323:1106.

11. Hudson JN. Computer-aided learning in the real world of medical education: does the quality of interaction with the computer affect student learning? Med Educ. 2004;38:887-895.

12. Simonsohn AB, Fischer MR. Evaluation of a case-based computerized learning program (CASUS) for medical students during their clinical years. Dtsch Med Wochenschr. 2004;129:552-556.

13. Gibbons NJ, Evans C, Payne A, Shah K, Griffin DK. Computer simulations improve university instructional laboratories. Cell Biol Educ. 2004;3(4):263-269.

14. Hahne AK, Benndorf R, Frey P, Herzig S. Attitude towards computerbased learning: determinants as revealed by a controlled interventional study. Med Educ. 2005;39(9):935-943.

15. Link TM, Marz R. Computer literacy and attitudes towards e-learning among first year medical students. BMC Med Educ. 2006;6:34.
Advances in Medical Education and Practice

\section{Publish your work in this journal}

Advances in Medical Education and Practice is an international, peerreviewed, open access journal that aims to present and publish research on Medical Education covering medical, dental, nursing and allied health care professional education. The journal covers undergraduate education, postgraduate training and continuing medical education

\section{Dovepress}

including emerging trends and innovative models linking education, research, and health care services. The manuscript management system is completely online and includes a very quick and fair peer-review system. Visit http://www.dovepress.com/testimonials.php to read real quotes from published authors. 